\title{
Els verbs de canvi d'estat del català i l'alternança causativa: una proposta sintàctica
}

\section{Catalan Change-of-State Verbs and the Causative Alternation: a Syntactic Proposal}

\author{
Bartomeu Abrines Llabrés [babrines@uoc.edu] \\ Universitat Oberta de Catalunya, Espanya \\ Jaume Mateu Fontanals [jaume.mateu@uab.cat] \\ Universitat Autònoma de Barcelona / Centre de Lingüística Teòrica, Espanya
}

\begin{abstract}
RESUM
En aquest treball analitzem la participació dels verbs de canvi d'estat del català en l'alternança causativa. En revisem les classificacions fetes, però finalment les rebutgem per la seva insuficiència empírica i teòrica. Analitzem especialment la participació dels verbs de canvi de causa interna en l'alternança i els casos en què legitimen la construcció causativa fins i tot amb un subjecte agentiu. Per tal d'explicar aquests casos, postulem la necessitat d'un principi cognitiu que complementi la Direct Causation Condition proposada per Rappaport Hovav i Levin (2012). Aquesta anàlisi, i la de la legitimació dels adjunts agentius o causals en les construccions de l'alternança i de les passives, ens menen a postular, seguint l'enfocament neoconstruccionista d'Alexiadou, Anagnostopoulou i Schäfer (2015), cinc estructures sintàctiques que donin compte del seu comportament sintàctic. En conclusió indiquem que només la diferència entre arrels que lexicalitzen la manera o l'estat resultant és pertinent per explicar la participació de les arrels en l'alternança.
\end{abstract}

\section{Paraules Clau}

Verbs de canvi d'estat; alternança causativa; estructura argumental sintàctica; català

\section{Abstract}

We deal with the participation of Catalan change-of-state verbs in the causative alternation. After revising some previous classifications, we finally discard them due to their theoretical and empirical insufficiency. We specially focus on internally caused change-of-state verbs, which have traditionally been said not to enter the causative alternation, and we also analyse the cases where these verbs enter the transitive construction even with an agentive external argument. We claim that a cognitive principle is needed, in addition to the Direct Causation Condition, in order to explain these cases. Our analysis, which also takes into account the licensing of agentive and causal adjuncts in alternant and passive constructions, leads us to propose, following the neoconstructionist perspective put forward by Alexiadou, Anagnostopoulou \& Schäfer (2015), five syntactic structures to explain their syntactic behaviour. In conclusion, we point 
out that it is only the difference between manner and result roots that is relevant to explain how roots participate in the causative alternation.

\section{KEYWORDS}

Change-of-state verbs; causative alternation; syntactic argument structure; Catalan

REBUT 2018-03-01; ACCEPTAT 2018-05-06

Volem agrair els suggeriments i comentaris constructius de dos revisors anònims. El segon autor d'aquest article agraeix també el suport dels projectes FFI2014-56968-C4-1-P (MINECO) i 2017SGR-634 (Generalitat de Catalunya)

\section{Introducció}

L'alternança causativa és una alternança d'estructura argumental que caracteritza una sèrie de verbs que poden tenir un ús transitiu i un d'intransitiu, d’entre els quals sens dubte els més importants són els verbs de canvi d'estat. Sintàcticament, el sintagma que funciona com a objecte en l'alternant transitiu passa a ser subjecte en l'intransitiu, com podem veure a (1):

(1) a. En Joan va rompre el vidre del cotxe.

b. El vidre del cotxe es va rompre.

Semànticament, el significat de les dues variants està relacionat. Així, (1b) denota un esdeveniment en què una entitat canvia d'estat, sense que calgui expressar qui o què l'ha provocat. En canvi, (1a) denota un esdeveniment en què una entitat provoca o causa el canvi d'estat. Així doncs, podem dir que el significat de la variant transitiva és 'causar $+V_{\text {intransitiu}}$ ' L'alternant transitiu rep el nom de causatiu, mentre que l'intransitiu ha rebut, a més dels d'incoatiu o ergatiu, el d'anticausatiu.

Haspelmath (1993) va diferenciar inicialment dos tipus d'alternança: la causativa i l'anticausativa, segons la direcció que pren la derivació. En la primera, la construcció bàsica és la intransitiva, mentre que en la segona ho és la transitiva, perquè l'altra variant, en tots dos casos, pren alguna marca morfològica. ${ }^{1}$

En català, l'alternança pren la forma anticausativa, perquè és la variant intransitiva la més complexa morfològicament (1b), ja que al verb s'hi afegeix un clític pronominal que coincideix amb el clític reflexiu. ${ }^{2}$

1 Haspelmath assenyala un tercer tipus d'alternança, en què cap de les dues variants no deriva de l'altra (nondirected alternation), amb tres subclasses: totes dues variants deriven d'una mateixa arrel que expressa la situació bàsica (equipollent alternation), s'usen diferents arrels per a expressar les dues variants (suppletive alternation), o s'usa la mateixa arrel sense marcatge per a les dues variants (labile alternation).

2 També podem trobar alguns verbs que usen la mateixa arrel sense marcatge morfològic en cap de les dues variants, és a dir, que no prenen el clític se en la variant intransitiva, i alguns verbs que la marquen de manera opcional. A Abrines (2016) s'estudien més detingudament. 
Els treballs sobre l'alternança causativa, originats en l'anàlisi de la interfície entre el lèxic i la sintaxi, s'han adreçat sobretot a tractar alguns aspectes controvertits de l'alternança, entre els quals podem destacar els següents:

(i) La determinació de quina de les dues variants és bàsica i quina derivada.

(ii) La delimitació de les característiques estructurals de les dues variants.

(iii) La justificació teòrica de la variació en la distribució morfològica que trobem interlingüísticament entre les dues variants.

(iv) Les diferències entre les construccions anticausatives i les passives i també amb altres construccions amb les quals coincideixen pel fet de prendre el clític pronominal se.

Aquest article s'estructura de la manera següent. Primerament es fa un repàs breu d'algunes classificacions rellevants dels verbs de canvi d'estat (apartat 2) i posteriorment s'analitza la seva participació en l'alternança causativa en català (apartat 3). En l'apartat 4 es compara el comportament sintàctic de les variants causativa i anticausativa amb el de les construccions passives, per ajustar la proposta d'estructures sintàctiques que representin aquestes construccions (apartat 5). Finalment, l'apartat 6 conté les conclusions.

\section{Els verbs de canvi d'estat}

Rappaport Hovav i Levin (1998: 101-102) defineixen els verbs de canvi d'estat de la manera següent:

A verb of change of state, such as break, $d r y$, or widen, as the name implies, lexicalizes a particular achieved state, and the verb denotes the bringing about this state. But though the verb itself denotes the bringing about of this state, it leaves the nature of the causing activity involved unspecified; that is, such verbs do not lexicalize a manner.

Aquestes dues autores en proposen una primera classificació en dos tipus: verbs de causa interna (blossom, grow o wilt) i de causa externa (break, open o dry). ${ }^{3}$ També prevenen del fet que la caracterització que en fan es basa en la intuïció: la distinció és en la manera com els esdeveniments es conceptualitzen i no en com són en el món real.

Per altra banda, cal destacar que, segons aquestes autores, la classificació en un o altre grup és determinant amb vista a la participació en l'alternança causativa. Els verbs de causa externa participen en l'alternança, mentre que els de causa interna no hi participen.

Altres classificacions han subdividit els verbs de causa externa de Levin i Rappaport Hovav en dos (o tres) tipus diferents, a causa que n'hi ha una part que no participen normalment de l'alternança. ${ }^{4}$ Així doncs, aquestes propostes ajusten la classificació a les dades empíriques de participació en l'alternança.

3 Mendikoetxea (1999) reprèn aquesta classificació i l’aplica al castellà.

4 És evident que Levin i Rappaport Hovav s'havien adonat d’aquesta circumstància. Per mantenir la classificació indicaven que la participació en l'alternança no depenia només de factors sintàctics sinó també de factors semàntics. 


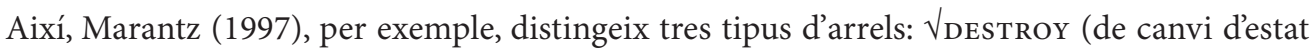
de causa externa o agentivitat), $\sqrt{\text { GROW }}$ (de causa interna) i $\sqrt{\text { BREAK }}$ (d'estat resultant). Per altra banda, Harley i Noyer (2000) distingeixen també tres classes de verbs: de causació interna, de causació externa i inespecificats. Finalment, Alexiadou, Anagnostopoulou i Schäfer [AAS] (2006) classifiquen les arrels dels verbs de canvi d'estat segons la seva semàntica enciclopèdica. Distingeixen, així, quatre tipus d'arrels: agentives (assassinate), de causa interna (blossom), de causa externa (destroy) i de causa no especificada (break).

Segons aquests últims autors, en les arrels agentives la causa de l'esdeveniment requereix la presència d'un agent, la qual cosa impedeix que alternin. En les arrels de causa interna la causa de l'esdeveniment de canvi està relacionada amb les propietats inherents a l'argument que sofreix el canvi. Aquestes arrels no poden formar la variant causativa de l'alternança, però sí que poden causativitzar de manera indirecta. En canvi, en les arrels de causa externa el canvi és causat per un argument diferent del que el pateix. Segons els autors, poden alternar en certes llengües (p.ex., el grec), però no en altres (p.ex., l’anglès). Finalment, en les arrels de causa no especificada no trobam particularització respecte d'una causa interna o externa i alternen en totes les llengües.

Resumim aquestes quatre propostes en la Taula 1, atès que la terminologia que els autors usen no és sempre coincident.

\begin{tabular}{|l|l|l|l|}
\hline $\begin{array}{l}\text { Levin } \text { i Rappaport } \\
\text { Hovav (1995) }\end{array}$ & Marantz (1997) & Harley i Noyer (2000) & AAS (2006) \\
\hline $\begin{array}{l}\text { Verbs de causa } \\
\text { externa }\end{array}$ & $\begin{array}{l}\text { Arrels de causa externa } \\
\text { o agentivitat }\end{array}$ & $\begin{array}{l}\text { Verbs de causació } \\
\text { externa }\end{array}$ & Arrels agentives \\
\cline { 2 - 4 } & Arrels d'estat resultant & Verbs inespecificats & $\begin{array}{l}\text { Arrels de causa } \\
\text { inespecificada }\end{array}$ \\
\hline $\begin{array}{l}\text { Verbs de causa } \\
\text { interna }\end{array}$ & Arrels de causa interna & $\begin{array}{l}\text { Verbs de causació } \\
\text { interna }\end{array}$ & Arrels de causa interna \\
\hline
\end{tabular}

Taula 1: classificacions dels verbs de canvi d'estat

Aquestes classificacions han mostrat la seva insuficiència empírica i teòrica. Empíricament, la participació en l'alternança s’escapa de la classificació, ja que la casuística mostra que el comportament de les arrels és molt divers i que podem trobar arrels que es podrien classificar de manera diferent $i$ arrels que presenten restriccions a alternar segons el context. En aquest sentit, les classificacions s'han fet per ajustar la participació dels verbs en l'alternança, per la qual cosa cauen en la circularitat: es defineix un verb per la participació o no en l’alternança i alhora la participació en l'alternança depèn de la classificació de les arrels.

Teòricament, AAS (2015) per exemple, qüestionen que la participació en l'alternança depengui de la caracterització semàntica de les arrels, és a dir, que estigui codificada com un tret de l'arrel que participa en la formació del verb. Els autors es demanen per què les arrels haurien de ser classificades a partir d'una propietat rellevant, si segons la Distributed Morphology [DM] són categorialment neutres. D’acord amb Acedo-Matellán i Mateu (2014), si les arrels són opaques 
pel que fa a la computació sintàctica, qualsevol classificació ontològica esdevé espúria per als propòsits de la gramàtica.

A continuació analitzarem el comportament dels verbs de canvi d'estat en l'alternança causativa.

\section{La participació dels verbs en l'alternança causativa}

Per analitzar la participació en l'alternança causativa seguirem els diferents tipus d'arrels d'AAS (2006).

\subsection{Arrels agentives i de causa externa}

En relació amb les arrels agentives i de causa externa, totes les classificacions vistes coincideixen a destacar que no participen en l'alternança. Sintàcticament la diferència entre tots dos tipus és que els verbs de causa agentiva únicament legitimen la construcció amb un subjecte AGENT, mentre que els de causa externa també en legitimen un d'INSTRUMENT o CAUSA:

(2) a. En Joan va assassinar en Pere.

b. ${ }^{\star}$ La destral va assassinar en Pere.

c. ${ }^{\star}$ La caiguda va assassinar en Pere.

(3) a. En Joan va destruir el seu cotxe.

b. La màquina va destruir la pedra.

c. L'epidèmia va destruir la població.

Cap dels dos tipus d'arrels no permet, però, un alternant anticausatiu:

(4) a. ${ }^{\star}$ En Pere es va assassinar.

b. ${ }^{\star}$ El seu cotxe es va destruir.

Així i tot, la diferència entre (4a-b) és que en el segon cas la construcció intransitiva es pot interpretar com de passiva pronominal, ja que legitima adjunts orientats a l'agent o clàusules finals (p.ex., vid. Bartra 2002, i.a.):

(5) a. ${ }^{\star}$ En Pere es va assassinar \{intencionadament / per cobrar l'assegurança\}.

b. El seu cotxe es va destruir \{intencionadament / per cobrar l’assegurança\}.

Tanmateix, altres verbs d'arrel agentiva sí que legitimen la construcció de passiva pronominal:

(6) a. El joc es va legalitzar per evitar l'existència de les màfies.

b. El bacallà es va dessalar per aconseguir un plat millor. 
Per altra banda, AAS (2006: 180) indiquen que la possibilitat de participar en l'alternança està restringida a una part dels verbs de canvi d'estat mitjançant una generalització que reproduïm a continuació: «The transitive verbs that cannot form anticausatives restrict their subjects to agents or agents and instruments and disallow causers.» Així i tot, a (3) hem comprovat que destruir no presenta restriccions i tampoc no participa en l'alternança. Per tant, aquesta qüestió ens l'hauríem de plantejar des de dues perspectives diferents: per què els verbs agentius no poden alternar, però també per què hi ha verbs que no poden alternar tot i legitimar arguments externs causa, contràriament a la generalització.

Tanmateix, una qüestió queda ara oberta: hem de diferenciar dos tipus de verbs diferents (agentius i de causa externa) o hem de considerar que els de causa externa no existeixen i són simplement una excepció a la restricció sobre l'argument extern dels verbs que no alternen?

Segons Marantz (2001), el verb destruir, com altres verbs amb la mateixa arrel, no alterna perquè presenta una estructura sintàctica diàdica. Així, segons l'autor, aquest verb prové d'una arrel de manera $(\sqrt{ } \mathrm{STROY})$, a la qual s'incorpora una partícula resultativa, pronunciada de-, que pren un subjecte intern com a objecte directe de la derivació. Per tant, la presència de l'arrel de manera explicaria que aquests verbs no legitimin la variant anticausativa. De fet, Marantz (2005) relaciona l'obligatorietat d'un argument extern agentiu amb la presència d'arrels de manera $i$, per tant, amb arrels que participen en estructures sintàctiques amb un nucli verbal funcional que correspon a una activitat i no a un canvi d'estat.

D’acord amb la cita següent extreta de Rappaport Hovav i Levin (2012: 160), els verbs agentius no alternen perquè lexicalitzen la manera i no el resultat.

Based on these properties, we propose that these verbs are lexically specified for two arguments, a theme argument and a cause argument; that is, they are inherently dyadic. Furthermore, they lexically restrict their cause argument to being an agent. We propose that this additional lexical restriction prevents the cause argument from being removed by an arity operation. In contrast, verbs showing the causative alternation do not impose any selectional restriction on their cause subjects-as Reinhart claims-and we take this property to indicate that these verbs are inherently monadic.

Per la seva banda, Rappaport Hovav (2014) planteja una distinció entre verbs lèxicament associats amb un argument que representa la causa externa, tant si especifiquen quelcom sobre la natura de la participació d'aquest argument (tipus assassinar) com si no n'especifiquen res (tipus destruir), i verbs que estan associats només amb l'argument intern que pateix el canvi d'estat. Els primers no alternarien i els segons, en canvi, sí. Els primers lexicalitzen la manera; els segons, el resultat. ${ }^{5}$

Tanmateix, també podem aportar exemples de participació en l'alternança d'aquests tipus de verbs:

(7) a. Pel que fa al suport, el paper es destrueix i la llauna es rovella.

b. El pas del temps destrueix el paper i rovella la llauna.

5 Sobre la complementarietat entre els components de manera i resultat, es poden consultar entre d'altres Arsenijević (2010), Beavers i Koontz-Garboden (2012), Levin i Rappaport Hovav (2008, 2013), Mateu i Acedo-Matellán (2012), Rappaport Hovav i Levin (2010). 
(8) a. Quan aquest temps és massa curt, la regulació ecològica no funciona, l’ecosistema es desequilibra i es destrueix.

b. L'acció humana desequilibra el sistema i el destrueix.

(7a-8a) recullen dues construccions -extretes del DDLC (Diccionari Descriptiu de la Llengua Catalana) - en què el verb destruir s'usa intransitivament i que podrien ser sense problemes la variant anticausativa de $(7 \mathrm{~b}-8 \mathrm{~b}){ }^{6}$

Així doncs, els verbs agentius i de causa externa no participen en l'alternança. La variant intransitiva d'aquests verbs s'ha de considerar, quan es legitima, com una passiva pronominal. De tota manera cal revisar la generalització d'AAS (2006), ja que verbs que no restringeixen el seu argument extern tampoc no participen de l'alternança.

\subsection{Arrels de causa inespecificada}

Conformen el grup dels verbs de canvi d'estat de causa inespecificada un ampli ventall de verbs que participen tots en l’alternança causativa. A continuació n’oferim alguns exemples:

(9) a. La tempesta ha enfonsat el vaixell.

b. El vaixell s'ha enfonsat.

(10) a. En Joan ha empitjorat la seva salut.

b. La seva salut ha empitjorat.

(11) a. Lallau va bloquejar el camí cap al cim.

b. El camí cap al cim es va bloquejar.

(12) a. L'aparició d'un crui ha buidat la piscina

b. La piscina s'ha buidat.

Tanmateix, és important indicar que, tot i la regularitat que sembla que mostren, també trobem algunes restriccions semàntiques pel que fa als elements que poden aparèixer com a objecte en la variant causativa i com a subjecte en l'anticausativa. ${ }^{7}$ Levin i Rappaport Hovav (1995) indiquen que el conjunt d’elements que poden aparèixer com a objecte és més nombrós que el dels que poden aparèixer com a subjecte en la variant intransitiva dels mateixos verbs, i indiquen que aquest fenomen és força general. Alguns exemples en català són els següents:

6 Podria argüir-se, en aquests casos de (7a) i (8a), que el verb destruir s'interpreta amb el significat de "desintegrar" i, per tant, no hi hauria un component de manera implicat, cosa que facilita l'alternança.

7 Aquest fet demostraria que els aspectes semàntics rellevants que determinarien la participació en l’alternança no estan relacionats únicament amb l’arrel, sinó amb l’esdeveniment denotat per la conjunció del predicat i els seus arguments interns (Schäfer 2009). Per altra banda, Rappaport Hovav (2014) també reporta un altre tipus de restricció: verbs que segons l'argument només es construeixen en la variant intransitiva. L'autora indica que aquest fet només demostra que cal formular de manera més precisa les condicions sota les quals es legitima o s'impedeix l'aparició d'un argument causa. 
(13) a. En Joan ha romput \{la finestra / la seva promesa / el contracte / el rècord del mon\}.

b. $\quad\left\{\right.$ La finestra $/{ }^{\star}$ La seva promesa $/{ }^{\star}$ El contracte $/{ }^{\star}$ El rècord del mon $\}$ s'ha romput. ${ }^{8}$

(14) a. L'arribada d'en Joan va animar la festa.

b. La festa es va animar.

c. El govern va animar la declaració d'independència.

d. ${ }^{\star}$ La declaració d’independència es va animar.

(15) a. Les declaracions del president van reduir la tensió entre els països.

b. La tensió entre els països es va reduir.

c. En Joan va reduir la fracció matemàtica.

d. ${ }^{\star}$ La fracció matemàtica es va reduir.

En realitat, però, passa que la construcció causativa en aquests casos demana un argument extern agentiu, per la qual cosa la construcció intransitiva es pot entendre com de passiva pronominal:

(16) a. $\{$ En Joan / El vent $\}$ va obrir la porta.

b. La porta es va obrir.

c. En Joan va obrir \{la carta / el testament $\}$.

d. ${ }^{*}\{$ La carta / el testament $\}$ es va obrir. [gramatical com a passiva pronominal]

Aquest fet permet considerar que, en aquelles construccions en què l'argument extern és agentiu, la intransitiva sempre s'ha de considerar de passiva pronominal, encara que construccions amb el mateix verb es puguin interpretar com a anticausatives si l'argument extern rep el paper tema (Abrines 2016). Així, la conceptualització dels esdeveniments determinaria la legitimació de les construccions. Si un predicat s'interpreta en el sentit que és agentiu, aleshores no participarà de l'alternança i la variant intransitiva, si és acceptable, serà de passiva pronominal. En canvi, si el predicat s'interpreta de manera inespecificada, l'argument extern podrà ser AGENT O CAUSA i la variant intransitiva serà anticausativa, si correspon a la causativa amb argument CAUSA, o passiva pronominal, si correspon a la causativa amb argument extern AGENT.

De fet, Rappaport Hovav i Levin (2012: 158, nota 5) fan esment que qualsevol proposta que postuli l'existència de restriccions lèxiques en el verb per justificar la possibilitat de participació en l'alternança, s'haurà de plantejar el "problema" de l'aparent influència del context.

Per la seva banda, Schäfer (2009) també explica aquestes restriccions en el sentit que el coneixement del món fa que l'esdeveniment descrit es vegi només possible amb un argument extern agentiu.

8 Aquests exemples són la traducció del Levin i Rappaport Hovav (1995: 85). Rappaport Hovav i Levin (2012) i Rappaport Hovav (2014) n’ofereixen alguns més. 


\subsection{Arrels de causa interna}

Com ja hem vist, segons Levin i Rappaport Hovav (1995), en els verbs de causa interna és una propietat inherent a l'únic argument del verb la que provoca el canvi d'estat, per la qual cosa no poden alternar. També AAS (2006: 205) indiquen que aquest tipus d'arrels no poden expressar un esdeveniment causat per un argument extern, encara que segueixin sent causatius:

We assume that this follows from the encyclopaedic meaning of internally caused roots which tell us that properties of the internal argument are highly involved in the bringing about the change of state. Therefore, whenever these roots are combined with causers these can only be interpreted as indirectly facilitating the change of state of the theme. Note that while internally caused verbs do not transitivize they nevertheless can be causativized in the periphrastic causative construction, which expresses an indirect causation. This means that the concept of internal causation does not exclude any type of causativization per se, but only direct causation [...].

Tanmateix, estudis recents (McKoon i Macfarland 2000; Wright 2001, 2002; Rappaport Hovav i Levin 2012; Alexiadou 2014, i Rappaport Hovav 2014), han canviat la perspectiva d'anàlisi d'aquest tipus de verbs i han destacat que també participen de l'alternança, tot i que amb restriccions importants pel que fa als subjectes que legitimen.

Alexiadou (2014), a partir de Wright (2001,2002), indica que els verbs de canvi d'estat de causa interna es diferencien dels de causa inespecificada en tres aspectes. En primer lloc, perquè presenten restriccions importants pel que fa als subjectes que permeten. En segon lloc, perquè mostren fenòmens de gradació, és a dir, que no tots mostren la mateixa facilitat per alternar. Segons l'autora, en aquest sentit es dona una important correlació entre la possibilitat d'alternar i la possibilitat de dur subjectes animats. I, en tercer lloc, perquè les construccions causatives amb aquests verbs es veuen com a més acceptables si l'argument en la posició de subjecte duu algun modificador, cosa que no passa amb les construccions amb verbs de causa inespecificada. ${ }^{9}$ El problema prové precisament de la dificultat de definir què desencadena un esdeveniment de canvi de causa interna, ja que la noció de propietats inherents de l'entitat que pateix el canvi no sembla suficient. Per exemple, és clar que, quan una planta floreix, podem dir que és una propietat inherent a aquesta la que ho possibilita. Tanmateix, això sovint no és possible si algú no ha posat abans les condicions necessàries perquè l'esdeveniment tengui lloc (ha sembrat una llavor, ha regat) i ha cooperat en el canvi d'estat. ${ }^{10}$

9 Els exemples d'aquest darrer aspecte que Alexiadou (2014: 888 (16)) indica són els següents:

(i) a. ?Last July, sunlight wilted the begonias.

b. Last July, the intense sunlight wilted the begonias.

c. ?This past summer, moisture rotted the tomatoes.

d. This past summer, extremely moist conditions rotted the tomatoes.

10 Rodríguez (2011) reflexiona sobre aquesta dificultat de definició i compara que són també les propietats inherents d'una barra de ferro les que fan possible que es dobli. L'autor assenyala que altres objectes, com un diamant, per exemple, no tenen aquestes propietats. És a dir, que serien també les propietats inherents a una moneda, per exemple, les que farien que s'enfonsés, mentre que les d’un flascó de vidre tancat farien que surés. En aquest sentit, també serien les propietats inherents a un vaixell les que farien possible que s'enfonsés en determinades circumstàncies. 
Per tant, cal determinar en quins casos els verbs de causa interna permeten usos causatius i concretament amb subjectes agentius. A Abrines (2016) es parteix dels verbs que Levin i Rappaport Hovav (1995) i Mendikoetxea (1999) assenyalen com de causa interna per analitzar la participació en l'alternança d'aquest tipus d'arrels.

En principi, molts dels verbs que aquestes autores indiquen poden ser considerats també de causa inespecificada, ja que efectivament poden indicar un procés iniciat per un agent o una causa externa que repercuteix en l'argument intern o també un procés intern a aquest argument: aclarir, bullir, eixamplar, entelar, erosionar, inflar o refredar. Per tant, són verbs que es poden conceptualitzar de manera diferent.

Pel que fa als verbs deadjectivals o denominals de canvi d'estat amb el prefix en-, podem distingir els que denoten processos interns d'una persona o d'un esser animat (engreixar, envermellir, empal.lidir, envellir, emmalaltir) i els que també poden aplicar-se a objectes (enfosquir, empobrir, ennegrir, empitjorar). Els primers denoten clarament un esdeveniment de canvi de causa interna. Quan algú envermelleix o emmalalteix, el nostre coneixement del món ens permet de saber que hi pot haver una causa externa. Però el procés que designen els predicats es produeix internament. Només en són visibles les conseqüències. Podem veure una persona que està vermella o malalta, però és difícil observar el procés complet.

Aquests verbs no participen fàcilment de l'alternança, ja que no legitimen la construcció causativa si no és la perifràstica amb el verb fer.

(17) a. ${ }^{\star}$ En Joan va envermellir na Maria.

b. En Joan va fer envermellir na Maria.

c. Na Maria va envermellir.

De tota manera, una consulta al DDLC mostra que el comportament d'aquest verbs també és variable, ja que en certs casos podem trobar-hi construccions causatives. ${ }^{11}$

Els verbs que denoten processos en altres objectes, en canvi, sí que participen de l'alternança amb subjectes CAUSA, tot i que no rebutgen els subjectes agentius. En aquests darrers casos, però, la conceptualització dels esdeveniments és que l’agent no és la causa directa del canvi, sinó alguna acció que ha fet aquest agent:

(18) a. \{La crisi bancària / En Joan\} va empobrir en Miquel.

b. En Miquel es va empobrir.

Els altres verbs de causa interna van ser analitzats inicialment per McKoon i Macfarland (2000) i Wright (2001), i per Rodríguez (2011) per a l'espanyol. A Abrines (2016) se n'analitzen les aparicions en el CTILC (Corpus Textual Informatitzat de la Llengua Catalana). Els resultats de la recerca es mostren a la Taula $2 .^{12}$

11 Alguns exemples extrets del DDLC serien els següents:

(i) a. La hipocresia m’envermellí les galtes.

b. La sopa de la caserna t'engreixarà.

c. La fadiga l'emmalaltí.

12 En la columna Ocurrències indiquem els casos tenguts en compte dels trobats en una recerca a partir del participi masculí. Posteriorment, les que eren en construcció transitiva o intransitiva i el percentatge de les segones. Finalment, els casos en què la intransitiva prenia el clític pronominal o no el prenia. 


\begin{tabular}{|l|c|c|c|c|c|c|}
\hline Verb & Ocurrències & Transitives & Intransitives & $\%$ & - se & + se \\
\hline Germinar & 19 & 0 & 19 & 100 & 19 & 0 \\
\hline Fermentar & 11 & 0 & 11 & 100 & 11 & 0 \\
\hline Brostar & 2 & 0 & 2 & 100 & 2 & 0 \\
\hline Mustiar & 2 & 0 & 2 & 100 & 0 & 2 \\
\hline Oxidar & 4 & 0 & 4 & 100 & 0 & 4 \\
\hline Florir & 156 & 5 & 151 & 96,79 & 147 & 4 \\
\hline Brotar & 23 & 1 & 22 & 95,65 & 22 & 0 \\
\hline Rovellar & 8 & 1 & 7 & 87,5 & 0 & 7 \\
\hline Podrir & 20 & 3 & 17 & 85 & 0 & 17 \\
\hline Marcir & 28 & 7 & 21 & 75 & 3 & 18 \\
\hline Pansir & 10 & 3 & 7 & 70 & 0 & 7 \\
\hline Inflar & 41 & 14 & 27 & 65,85 & 0 & 27 \\
\hline Mudar & 124 & 23 & 81 & 65,32 & 67 & 14 \\
\hline Descompondre & 15 & 6 & 9 & 60 & 0 & 9 \\
\hline Erosionar & 4 & 2 & 2 & 50 & 0 & 2 \\
\hline Corcar & 8 & 4 & 4 & 50 & 0 & 4 \\
\hline Corrompre & 36 & 25 & 11 & 30,56 & 0 & 11 \\
\hline Corroir & 4 & 4 & 0 & 0 & & \\
\hline
\end{tabular}

Taula 2: Percentatge d'ocurrències com a intransitius de verbs de causa interna

Crida l'atenció, en primer lloc, l'alt percentatge d'aparicions d'aquests verbs en contextos intransitius. De fet, n’hi ha set que hi apareixen més d'un 95\% dels casos, cinc dels quals ho fan en un $100 \%$. Es tracta dels verbs brotar, florir, oxidar, mustiar, brostar, fermentar i germinar.

A continuació, en trobem quatre que presenten també un percentatge bastant alt d'ocurrències com a intransitius (entre el 70\% i el 95\%): rovellar, podrir, marcir i pansir.

Finalment, la resta presenta un percentatge d'ocurrències com a intransitiu més aviat reduït, tot i que en la major part encara igual o superior al 50\%. Superen aquest 50\% inflar, mudar, descompondre, erosionar i corcar. En canvi, no arriba al 50\% corrompre. Per acabar, el verb corroir no presenta cap cas com a intransitiu.

Pel que fa a la possibilitat de ser construits amb un subjecte agentiu, Wright $(2001,2002)$ ja va advertir que el paper temàtic de les construccions causatives amb aquests verbs està molt restringit i que molt rarament legitimaven subjectes agentius. La seva explicació era de caràcter semàntic: els esdeveniments que aquests verbs expressen són conduïts per aspectes naturals. McKoon i Macfarland (2000) també exposen que la principal diferència entre verbs de causa inespecificada i interna és que els primers no presenten restricció pel que fa als subjectes de les variants causatives, mentre que els segons presenten majoritàriament subjectes que són entitats naturals. Tanmateix, Alexiadou (2014) proposa una anàlisi segons la qual cal esperar que els verbs de causa interna no restringeixin el paper temàtic dels subjectes de la construcció transitiva. 
Rappaport Hovav i Levin (2012: 166) recorren a la noció de causa directa per explicar les restriccions en els usos causatius dels verbs de canvi de causa interna. Una condició que expliqui quan pot aparèixer el subjecte que representa la causa d'un canvi d'estat: ${ }^{13}$

The Direct Causation Condition [DCC]: A single argument root may be expressed in a sentence with a transitive verb if the subject represents a direct cause of the eventuality expressed by the roots and its argument.

Segons aquestes autores, els esdeveniments que indiquen un canvi de causa interna només poden presentar com a causes les forces naturals o les condicions ambientals que desencadenen o faciliten el canvi, en ser-ne les causes immediates. Per contra, exemples d'aquests verbs amb subjectes agentius només serien acceptables si les forces naturals o els factors ambientals s'entenguessin com a instruments en mans de l'agent i no com a causes que intervenen en el canvi. Observem, tanmateix, que la noció de causa directa és semàntica i que depèn de la conceptualització dels esdeveniments. Per tant, és difícil determinar com es trasllada a la sintaxi.

Tanmateix, en català podem trobar contrastos com els següents:

(19) a. \{El pagès / la calor $\}$ ha assecat les figues.

b. Les figues s'han assecat.

c. $\{$ En Joan / El sol $\}$ ha pansit les olives.

d. Les olives s'han pansit.

(20) a. $\quad\left\{{ }^{*}\right.$ El fuster / La humitat $\}$ podreix la fusta.

b. La fusta es podreix.

c. $\left\{{ }^{\star}\right.$ En Joan / ??El corc / La falta de neteja $\}$ va corcar les dents.

d. Les dents es van corcar.

(21) a. $\quad\left\{{ }^{*} \mathrm{El}\right.$ jardiner $\left./{ }^{*} \mathrm{El} \mathrm{sol} \mathrm{i} \mathrm{la} \mathrm{humitat}\right\}$ van florir els rosers.

b. Els rosers van florir.

A (19) trobem exemples de verbs de causa interna que permeten subjectes agentius i causes naturals alhora. En canvi, a (20) només es legitimen les causes naturals, però no els subjectes agentius. I encara, a (21) trobem un verb de causa interna que no admet cap tipus de subjecte en la construcció causativa. Pel que fa als primers, és clar que les figues s'assequen i les olives es panseixen per un procés intern. Tanmateix, la conceptualització del món permet de construir aquests verbs amb subjectes agentius. Però, l'únic que poden fer les persones és facilitar o disposar les condicions oportunes per tal que les figues s'assequin o les olives es panseixin. Tot i això, en els altres casos el subjecte agentiu no es legitima encara que el vulguem entendre com a facilitador, o fins i tot no es legitimen tampoc les condicions naturals que provoquen el canvi.

13 La definició de les autores segueix la de Wolff (2003), segons la qual la causació directa necessita de dues condicions suplementàries: que no hi hagi entitats intermèdies del mateix tipus que el causant o el causat i que, si n'hi ha cap, sigui considerada com una condició que possibilita el canvi i no com una causa que hi intervé. 
En aquest sentit, creiem que la DCC pot explicar les construccions causatives amb verbs de causa inespecificada, però no els contrastos que hem vist. Potser podríem argumentar que a (19) l'agent controla, d'alguna manera, les condicions ambientals i que es pot entendre com a facilitador (segona condició de Wolff, vid. nota 13). El problema, però, és per quin motiu no s'accepta un subjecte agentiu en els casos de (20-21).

A més, si interpretem de manera més restrictiva la DCC, les condicions ambientals no són realment una mena d'instruments en mans de l'agent, sinó exactament a l'inrevés: són els agents els que funcionen com a facilitadors de les condicions ambientals, sense controlar-les. Per tant, la formulació de la DCC no pot explicar de manera adequada el comportament dels verbs de causa interna.

En aquest sentit, a Abrines (2016), on s'analitzen aquests fets de manera més extensa, es postula la necessitat d'un principi cognitiu que regeixi la legitimació de les construccions causatives amb verbs de causa interna. Horvath i Siloni (2011) ja van postular un principi d'aquestes característiques, tot i que era per explicar per què els verbs de causa agentiva no poden participar de l'alternança. Per la seva banda, Neeleman i Van de Koot (2012) també han presentat una mena de principi per justificar quan un subjecte pot ser agentiu. Es tracta del que anomenen responsabilitat (accountability). Segons la seva proposta, una entitat pot ser concebuda com a responsable d'una acció si s'entén que és l'argument que expressa el factor crucial de l'esdeveniment.

A Abrines (2016) es defensa que el principi cognitiu que regeixi la legitimació de les construccions causatives (especialment amb verbs de causa interna) ha d'estar relacionat amb la conceptualització que els parlants fan de l'esdeveniment. Així, una entitat (agentiva o no) pot funcionar com a subjecte d'una construcció causativa si el coneixement del món del parlant la veu com una causa possible de l'esdeveniment, encara que no en sigui la causa directa ni una entitat facilitadora. Aquesta proposta s'inscriu dins el consens cada cop més generalitzat a destacar la importància de la conceptualització dels esdeveniments en l'acceptabilitat de les diferents realitzacions argumentals d'un verb.

\section{Legitimació d'adjunts}

Schäfer (2008), Alexiadou (2010) i AAS (2015) proposen dues estructures sintàctiques diferents per representar la variant anticausativa, depenent de si està marcada morfològicament o no ho està. Per argumentar aquestes estructures, i diferenciar-les de les de passiva, analitzen la modificació dels verbs de canvi d’estat mitjançant adjunts que manifestin agentivitat o causa en diferents llengües.

En català les construccions anticausatives normalment estan marcades amb la presència del clític se, i coincideixen superficialment amb una construcció amb significat de passiva: la passiva pronominal. Aleshores, la comparació del comportament sintàctic d'ambdues construccions esdevé imprescindible per ajustar la proposta d'estructures sintàctiques. ${ }^{14}$

14 També les construccions anomenades mitjanes o pronominals genèriques (Bartra 2002) es relacionen amb les anticausatives perquè comparteixen morfologia. Tot i que també es van analitzar a Abrines (2016), requereixen una anàlisi més fina, per la qual cosa les hem deixat de banda en aquest treball, a l'espera de desenvolupar-ne un estudi més aprofundit. 
Les passives i les anticausatives difereixen en el fet que les primeres poden ser modificades per adjunts preposicionals que indiquen finalitat, adverbis orientats a l'agent o clàusules finals (Chiechia 2004; Levin i Rappaport Hovav 1995; Reinhart 2000). En canvi, les anticausatives legitimarien un adjunt by itself (per si sol) o adjunts causals amb les preposicions per i amb. ${ }^{15}$

En català, un verb que participa de l'alternança causativa es pot construir, en la forma de passiva perifràstica, amb un complement agent, un adverbi orientat a l'agent o una clàusula subordinada final:

(22) a. El vaixell va ser enfonsat \{pels pirates / intencionadament / per cobrar l'assegurança\}.

Tanmateix, en la construcció de passiva pronominal el complement agent no queda legitimat, i només hi queden els adverbis orientats a l’agent o les clàusules finals. Aquesta és la diferència fonamental entre totes dues construccions de passiva: l'acceptabilitat o no d'un adjunt agentiu introduït amb per. ${ }^{16}$ Aquesta diferència de comportament sintàctic s'ha de relacionar amb la diferència morfològica entre totes dues construccions: les passives perifràstiques es construeixen amb la veu passiva, mentre que les passives pronominals destaquen per la presència del clític pronominal se, tot i que el verb apareix en veu activa. Per tant, podem pensar que la presència del clític bloqueja l'expressió de l'argument extern agentiu.

(23) a. El vaixell es va enfonsar (= va ser enfonsat) $\left\{{ }^{*}\right.$ pels pirates / intencionadament / per cobrar l'assegurança\}.

Per tant, la conclusió és que les construccions de passiva pronominal no poden dur un agent explícit (ni tan sols en forma d'adjunt preposicional), tot i que implícitament l'hem d'interpretar, com ho demostraria que puguin dur altres adjunts orientats a l'agent.

En canvi, les construccions anticausatives no poden dur un adverbi orientat a l'agent o una clàusula final:

(24) a. ${ }^{*}$ El vaixell es va enfonsar \{intencionadament / per cobrar l'assegurança\}.

Així doncs, encara que superficialment idèntiques, les construccions anticausatives i de passiva pronominal no són semànticament equivalents.

Les anticausatives, a més, admeten un modificador que reforça la interpretació que el procés es desenvolupa sense la intervenció directa o activa d'un agent o d’una causa externa. Així

15 S'ha debatut si la legitimació d'aquests tipus d'adjunts causals demostra la presència d'un component de CAUSA en la representació lexicosemàntica o sintàctica de les anticausatives. Defensen que no tenen aquest component Härtl (2003), Neeleman i Van de Koot (2012), Piñón (2001a, 2001b) o Rákosi (2012) entre d’altres. Defensen que sí que el tenen en l'estructura lexicosemàntica Chierchia (2004), Levin i Rappaport Hovav (1995) o Mendikoetxea (1999). Alexiadou (2010), AAS $(2006,2015)$ o Schäfer (2008) postulen que les anticausatives tenen un nucli funcional anotat amb un tret de causa.

16 Tant la GIEC (2016: 504, 897) com Bartra (2002: 2155) indiquen que les construccions de passiva pronominal poden legitimar un complement agent introduit amb la locució per part de, tot i que esmenten que es tracta d'una construcció característica del llenguatge periodístic i administratiu i, segons Bartra, la passiva pronominal amb agent no és gaire natural en la llengua col·loquial. 
doncs, aquestes construccions legitimen adjunts com by itself en anglès, o per si sol / tot sol en català. ${ }^{17}$

(25) a. El vaixell es va enfonsar tot sol.

b. La piscina s'ha buidat tota sola.

En canvi, els verbs de passiva, perifràstica o pronominal, no admetrien aquest tipus d'adjunt:

(26) a. ${ }^{\star}$ El vaixell $\{$ va ser enfonsat $=$ es va enfonsar $\}$ per si sol.

Pel que fa a les preposicions usades, en català els adjunts agentius s'introdueixen amb per. En canvi, els adjunts de causa o instrument ho fan amb la preposició $a m b$. Tot i això, segons Rigau (2002), els complements agentius també es poden introduir amb de (p.ex. escrit de na Maria), i els adjunts de causa, amb per, de o a causa de.

(27) a. El vaixell es va enfonsar \{?per / amb / a causa de $\}$ \{la via d'aigua / la tempesta\}.

b. La teulada es va rompre $\{\mathrm{pel} / \mathrm{amb} / \mathrm{a}$ causa del $\}$ fort vent que bufava / terratrèmol\}.

Els verbs de canvi de causa interna també legitimen els adjunts de causa i l'adjunt de tipus tot sol i rebutgen els adjunts agentius.

(28) a. Les figues s'han assecat \{per / amb / a causa de\} la calor excessiva.

b. Les figues s'han assecat totes soles.

c. ${ }^{\star}$ Les figues s'han assecat \{intencionadament / per vendre-les\} [bona com a passiva pronominal\}

(29) a. L'escala s'ha rovellat \{per / amb / a causa de $\}$ l'aire humit.

b. Lescala s'ha rovellat tota sola.

c. ${ }^{\star}$ Lescala s'ha rovellat $\{$ intencionadament / per netejar-la

Pel que fa a les construccions de passiva, ni les perifràstiques ni les pronominals legitimen aquests adjunts de causa ni l'adjunt tot sol:

(30) a. ${ }^{\star}$ El vaixell $\{$ va ser enfonsat $=$ es va enfonsar $\}$ per / amb $\}$ la via d'aigua.

b. ${ }^{\star}$ El vaixell $\{$ va ser enfonsat $=$ es va enfonsar $\}$ tot sol.

En el quadre següent resumim les diferències entre aquests tipus de construccions:

17 A Abrines (2016) es mostra que aquests dos adjunts no són equivalents. Tot sol equivaldria a 'sense cap ajuda externa' en construccions causatives (si l'argument extern és agentiu); en canvi, en les anticausatives seria equivalent a per si sol i equivaldria a 'sense cap causa externa'. 


\begin{tabular}{|l|c|c|c|}
\hline Tipus d'adjunts & anticausatives & passives pronominals & passives perifràstiques \\
\hline Presència clític se & Sí & Sí & No \\
\hline Agentiu amb per & No & No & Sí \\
\hline De causa & Sí & No & No \\
\hline Orientat a l'agent & No & Sí & Sí \\
\hline Clàusules finals & No & Sí & Sí \\
\hline tot sol, per si sol & Sí & No & No \\
\hline
\end{tabular}

Taula 3: Legitimació d'adjunts en les diferents construccions en català

Aquest diferent comportament sintàctic ajudarà a definir les estructures sintàctiques d'aquestes construccions, com veurem en l'apartat següent.

\section{Estructures sintàctiques de les causatives, anticausatives i passives}

Una de les qüestions més debatudes sobre l'alternança causativa és si una variant deriva de l'altra. És a dir, si n'hi ha una que sigui la bàsica i de què derivaria l'altra mitjançant alguna operació sintàctica o lèxica. De fet, les primeres aproximacions a l'alternança assumien algun procés de derivació en el pas del lexicó a la sintaxi. Eren, per tant, teories de tipus projeccionista o, com les anomena Borer $(2004,2005)$, endo-skeletal.

Tanmateix, la possibilitat de realitzacions argumentals múltiples d'un mateix verb i les alternances argumentals, com la causativa, posaven en qüestió els postulats de les aproximacions projeccionistes, per la qual cosa s'han desenvolupat teories en què la interpretació dels arguments depèn de l'estructura sintàctica de les construccions més que no d'especificacions del significat lèxic del verb. En aquests models, el significat bàsic de l'arrel es combina amb el significat de l'estructura sintàctica i s'associa amb posicions estructurals particulars. Són teories de tipus construccionista o exo-skeletal.

Entre les aproximacions projeccionistes a l'alternança causativa, n'hi ha que consideren que la variant intransitiva deriva de la transitiva (Chierchia 2004; Härtl 2003; Koontz-Garboden 2009, o Reinhart 2000, 2003,2016) i n'hi ha que consideren que la causativa deriva de l'anticausativa (Hale i Keyser 1993, 2002; Rappaport Hovav 2014, i Rappaport Hovav i Levin 2012). En aquests models, l'expressió sintàctica dels arguments està codificada en l'entrada lèxica, una descomposició de predicats amb un component estructural i un d'idiosincràtic, relacionat amb l'arrel. En aquest cas, alguna operació que incorpora o elimina un dels elements de l'estructura lexicosemàntica determina la relació entre les dues variants.

En canvi, d’entre les propostes no derivacionals, és a dir, propostes que consideren que tant la variant anticausativa com la causativa s'originen a partir d'una mateixa arrel abstracta, podem destacar les següents: Alexiadou (2010), Alexiadou, Anagnostopoulou i Schäfer (2006, 2015), Doron (2003), Folli i Harley (2005, 2007), Harley (2013), Labelle i Doron (2010), Ramchand (2008) o Schäfer (2008). Aquests models postulen que les relacions temàtiques deriven de 
determinades posicions estructurals definides sintàcticament pels nuclis funcionals que participen en la representació sintàctica. Les dues variants, en aquest cas, no estan relacionades sintàcticament, sinó que totes dues són el producte de la incorporació de l'arrel en una o altra estructura, que es diferencien pels nuclis funcionals que contenen, i que determinen la diferent interpretació semàntica de les dues variants.

Per la nostra banda, per a la proposta d'estructures sintàctiques de les variants de l'alternança i de les passives, aprofundirem en la d'AAS (2015). Aquests autors parteixen d'una perspectiva neoconstruccionista i de les aportacions de la DM.

D’acord amb el que proposen, els anticausatius marcats morfològicament són intransitius en la semàntica, però transitius en la sintaxi. A més, assumeixen que la sintaxi no fa referència a trets semàntics en les arrels verbals, i que el significat causatiu es construeix a partir d'un nucli esdevenimental combinat amb algun element estatiu (una arrel, un adjectiu o un sintagma preposicional). Finalment, qüestionen el plantejament que la participació en l'alternança depengui de la caracterització semàntica de les arrels, ja que, segons la DM, són categorialment neutres i perquè fent-ho així es cau en la circularitat. Segons els autors, la participació en l'alternança, com defensem també nosaltres, depèn de la conceptualització dels esdeveniments.

Pel que fa a la representació sintàctica de les diferents variants, AAS (2015) parteixen de la base que l'alternança causativa és una alternança en el nucli funcional Voice. És a dir, que la variant transitiva d'aquesta alternança conté un nucli verbal que introdueix l'argument extern, mentre que la variant anticausativa manca d'aquesta capa verbal. Tanmateix, per explicar la presència d'anticausatius marcats morfològicament, els autors postulen que la seva representació sintàctica també conté un nucli funcional Voice semànticament buit, un expletive Voice. Aquest fet permet reanalitzar la intuïció teòrica que la morfologia en els anticausatius reflecteix l'absència d'argument extern i donar sentit a la tendència interlingüística que relaciona la distribució d'anticausatius marcats i no marcats amb la conceptualització dels esdeveniments, concretament de si es presenten com a espontanis o no. Aquesta hipòtesi ha estat defensada per Haspelmath (1993), Schäfer (2008), Heidinger (2014, 2015), o Alexiadou (2014). ${ }^{18}$

Per la nostra banda, plantegem de completar les estructures sintàctiques que AAS (2015) proposen per donar compte de les construccions causatives i anticausatives de l'alternança i de les passives, amb una nova estructura que justifiqui les construccions de passiva pronominal, que hem vist que són superficialment similars a les anticausatives, tot i que amb una semàntica i un comportament sintàctic diferents.

Així doncs, plantegem que el català disposa de cinc estructures sintàctiques per donar compte d'aquestes construccions. En aquestes estructures hi podem trobar tres nuclis funcionals diferents: Voice, Passive i Middle, cadascun amb una funció diferent. El primer s'encarrega de la

18 Segons aquesta hipòtesi, un esdeveniment que es conceptualitza amb alta probabilitat d'ocórrer de manera espontània tendirà a ser usat més aviat com a intransitiu i sense marcatge morfològic. En canvi, un esdeveniment amb baixa probabilitat d’ocórrer espontàniament tendirà a ser construït com a causatiu i amb el clític pronominal en la variant intransitiva. AAS (2015) assenyalen, però, que més recentment, i a partir de treballs sobre tipologia lingüística, aquest hipòtesi ha estat reemplaçada pel concepte de causalness: la proporció d'usos causatius o anticausatius d'un verb que alterna (Haspelmath et al. 2014). Així, l’espontaneïtat es reflectiria en la freqüència d'ús, en el sentit que com més espontani es pugui conceptualitzar un verb menys freqüentment ocorrerà en un context causatiu. 
introducció de l'argument extern, ja que essent temàtic el demana. ${ }^{19}$ Els nuclis Passive i Middle no són actius i, per tant, seguint la definició de passiva de Bruening (2013), es presenten amb una morfologia específica que impedeix la realització de l'argument extern. ${ }^{20} \mathrm{El}$ nucli Passive es realitza amb la veu passiva, mentre que el nucli Middle ho fa amb el clític pronominal se.

Finalment, en aquestes estructures fem abstracció de l'estructura del complement del verb, ja que aquest nucli esdevenimental $v$, que verbalitza l'arrel, es podria combinar amb una varietat d'elements, entre els quals hem d'esmentar les arrels mateixes, els adjectius o un sintagma preposicional.

Així doncs, les estructures proposades serien les següents:

\section{(31) Construccions transitivocausatives: [Voice [v [Root]]]}

En aquesta estructura trobem el nucli verbal Voice, que introdueix l'argument extern, i l'estructura que aporta el significat causatiu $(v+$ arrel $)$. Així doncs, aquesta estructura dona lloc a les construccions causatives amb un subjecte que s'interpreta com a CAUSA.

(32) Construccions de passiva perifràstica: [Passive [Voice [v [Root]]]]

En aquesta estructura el nucli Passive selecciona un nucli Voice, encarregat d'introduir l'argument extern. Però Passive impedeix que Voice el projecti. Atès el nucli Passive, l'estructura es construeix amb el verb en passiva i l’argument extern pot aparèixer explícitament com a adjunt.

(33) Construccions de passiva pronominal: [Middle [Voice [v [Root]]]]

En aquesta estructura trobem la combinació d'un nucli Middle i un de Voice, encarregat d'introduir l'argument extern. La presència del nucli Middle, però, ho impedeix, com a nucli que presenta una morfologia específica (el clític pronominal se) i pel significat passiu. Atès el nucli Middle, l'argument extern no pot aparèixer explícitament, però és present implícitament atès que el nucli Voice nés el responsable. Que la construcció admeti adjunts orientats a l'agent o clàusules finals ho demostra.

(34) Construccions anticausatives amb marcatge morfològic: [Middle [v [Root]]]

En aquesta estructura trobem el nucli Middle, però no el nucli Voice. Per tant, no és possible l’aparició de l'argument extern de manera explícita ni implícita. En canvi, la construcció legitima un adjunt del tipus per si sol amb el significat de 'sense cap causa externa' perquè la

19 No postulem l'existència de diferents flavors ('valors semàntics') de Voice per justificar la presència d'un nucli agentiu o un de causatiu perquè hem considerat que quan l'argument extern és agentiu, i la construcció no pot alternar, en realitat ens trobem davant d'una construcció amb un verb que lexicalitza la manera i, doncs, la construcció seria diàdica.

20 Bruening (2013:35) indica: «The passive is a morphosyntactic operation that prevents the realization of the external argument as an argument.» 
interpretació de $v$ és causativa. Atesa la presència de Middle, la construcció apareix amb el clític pronominal.

\section{(35) Construccions anticausatives sense marcatge morfològic: [v [Root]]}

Aquesta estructura no presenta ni el nucli Middle ni el nucli Voice. Per tant, no hi ha presència d'argument extern de manera explícita ni implícita, ni tampoc de la morfologia pròpia de les anticausatives marcades. De tota manera es preserva el significa causatiu gràcies a la combinació del nucli esdevenimental $v$ amb l'arrel que expressa estat resultant.

Pensem que aquestes representacions donen compte del comportament sintàctic dels verbs alternants. Totes les construccions que incorporen el nucli Voice inclouen un argument extern. En cas que el nucli Voice sigui únic, aquest argument es projecta en la posició d'especificador. En canvi, si aquest nucli està sota un nucli Passive o Middle, es veu impossibilitat de projectar-lo, ja que aquests altres nuclis lliguen existencialment l'argument extern. Amb Passive l'argument extern pot fer-se explícit com a adjunt, però amb Middle ha de restar implícit. D’aquesta manera queda reflectit a la sintaxi el fet que en les construccions de passiva perifràstica l'argument extern pugui aparèixer com a adjunt introduït amb la preposició per, però que les construccions de passiva pronominal no el legitimin.

El nucli Passive es realitza com a veu passiva, ${ }^{21}$ mentre que Middle es realitza en forma de clític pronominal se. Per això incorporen aquest clític les construccions anticausatives marcades i les de passiva pronominal. En les anticausatives marcades, però, no hi ha incorporat un nucli Voice, i no presenten un argument extern ni explícitament ni implícita. Les de passiva pronominal sí que el presenten.

Per altra banda, les construccions anticausatives, atesa la presència del nucli $v$, s'interpreten com a causatives i poden legitimar l'adjunt per si sol. Cap de les construccions que contenen Voice legitima aquest adjunt, perquè evidentment el nucli Voice està relacionat amb la presència d'un argument extern, és a dir, amb una causa.

Finalment, atès el consens creixent sobre la importància que té el coneixement del món en aquest àmbit d'estudi (Rappaport Hovav i Levin 2012; Rappaport Hovav 2014), proposem que la sintaxi ofereix el conjunt d'estructures indicat, en què les arrels poden incrustar-se lliurament, i que postsintàcticament el coneixement del món filtra les construccions resultants per determinar-ne l'acceptabilitat en un context concret. D'aquesta manera podem explicar el divers comportament sintàctic dels verbs de canvi d'estat, els quals, tot i seguir una línia general força delimitada, presenten comportaments sintàctics que s'escapen d'aquesta tendència.

En tractar la legitimació de subjectes agentius amb verbs de canvi de causa interna hem proposat la necessitat d'un principi cognitiu que complementi la DCC per explicar la legitimació de totes les construccions causatives.

21 Vegeu Bartra (2016) per a una anàlisi de la construcció passiva que no assumeix el nucli Passive com a element primitiu. 


\section{Conclusions}

Els estudis sobre l'alternança causativa s'han adreçat a analitzar-ne alguns aspectes controvertits com la determinació de la variant bàsica, la delimitació de les característiques estructurals d'aquestes construccions i la diferència amb les passives. En aquest treball hem analitzat l'alternança causativa en català $\mathrm{i}$ hem proposat les estructures sintàctiques de les construccions causativa i anticausativa i de les passives perifràstica i pronominal.

Els verbs de canvi d'estat són els que més prototípicament participen de l'alternança. Hem mostrat, però, la insuficiència de les classificacions que se n'han fet. Tanmateix, les hem recollit per analitzar la participació d'aquests verbs en l'alternança. La conclusió ha de ser que la participació en l'alternança causativa està guiada només per la diferenciació entre arrels que codifiquen l'estat resultant, que alternen, o la manera, que no ho fan. Incloem entre els segons aquells verbs de canvi que demanen un argument extern de tipus agentiu, per la qual cosa serien verbs amb dos arguments.

Entre els verbs que alternen ens hem estès en l'anàlisi dels verbs de causa interna, dels quals s'havia dit tradicionalment que no participaven de l'alternança. En aquest sentit, hem comprovat que n'hi ha molts pocs que es resisteixin a alternar i que la majoria poden fer-ho, fins i tot amb subjectes agentius, que són entesos com a facilitadors. Per explicar la legitimació de construccions causatives hem postulat la necessitat d'un principi cognitiu que complementi la DCC.

L’anàlisi de la participació amb l'alternança i de la legitimació d'adjunts finals i causals en les construccions causatives i anticausatives i en les de passiva ens ha permès postular cinc estructures sintàctiques que donen compte del comportament sintàctic dels verbs alternants. Segons la nostra proposta, les arrels s'incrusten lliurement en aquestes estructures i és postsintàcticament que el coneixement del món dels parlants en determina la felicitat.

\section{Referències bibliogràfiques}

Abrines, B. (2016). Els verbs de canvi d'estat i l'alternança causativa en català. Tesi doctoral. Universitat Autònoma de Barcelona.

Acedo-Matellán, V.; \& Mateu, J. (2014). From syntax to roots: A syntactic approach to root interpretation. In A. Alexiadou, H. Borer \& F. Schäfer (Eds.), The Syntax of Roots and the Roots of Syntax (pp. 14-32). Oxford-New York: Oxford University Press.

Alexiadou, A. (2010). On the morpho-syntax of (anti-)causative verbs. In M. Rappaport Hovav, E. Doron \& I. Sichel (Eds.), Lexical Semantics, Syntax, and Event Structure (pp. 177-203). Oxford-New York: Oxford University Press.

- (2014). The problem with internally caused change-of-state verbs. Linguistics, 52(4), 879-909.

Alexiadou, A.; Anagnostopoulou, E.; \& Schäfer, F. (2006). The properties of anticausatives crosslinguistically. In M. Frascarelli (Ed.), Phases of Interpretation (pp. 187-211). Berlin-New York: Mouton de Gruyter. . (2015). External Arguments in Transitivity Alternations: A Layering Approach. Oxford-New York: Oxford University Press. 
Arsenijević, B. (2010). Syntactic complexity and semantic opacity of manner in manner-expressing verbs. Manuscrit. Universitat Pompeu Fabra.

Bartra Kaufmann, A. (2002). La passiva i les construccions que s' hi relacionen. In J. Solà, M. R. Lloret, J. Mascaró \& M. Pérez Saldanya (Eds.), Gramàtica del català contemporani (pp. 2111-2179). Barcelona: Empúries.

- (2016). Els components de la passiva. Una perspectiva diacrònica. Caplletra, 61, 295-327.

Beavers, J.; \& Koontz-Garboden, A. (2012). Manner and result in the roots of verbal meaning. Linguistic Inquiry, 43(3), 331-369.

Borer, H. (2004). The grammar machine. In A. Alexiadou, E. Anagnostopoulou \& M. Everaert (Eds.), The Unaccusativity Puzzle: Explorations of the Syntax-Lexicon Interface (pp. 288-331). Oxford-New York: Oxford University Press.

— (2005). Structuring Sense. Volume II: The Normal Course of Events. Oxford-New York: Oxford University Press.

Bruening, B. (2013). By Phrases in Passives and Nominals. Syntax, 16(1), 1-41.

Chierchia, G. (2004). A semantics for unaccusatives and its syntactic consequences. In A. Alexiadou, E. Anagnostopoulou \& M. Everaert (Eds.), The Unaccusativity Puzzle. Explorations of the Syntax-Lexicon Interface (pp. 22-59). Oxford-New York: Oxford University Press.

Doron, E. (2003). Agency and voice: The semantics of the Semitic templates. Natural Language Semantics, 11(1), 1-67.

Folli, R.; \& Harley, H. (2005). Flavors of v. In P. Kempchinsky \& R. Slabakova (Eds.), Aspectual Inquiries (pp. 95-120). Dordrecht: Springer-Verlag.

- (2007). Causation, obligation, and argument structure: On the nature of little v. Linguistic Inquiry, 38(2), 197-238.

Gràcia i Solé, L. (1989). Els verbs ergatius en català. Ciutadella: Institut Menorquí d’Estudis.

Hale, K. L.; \& Keyser, S. J. (1993). On argument structure and the lexical expression of syntactic relations. In K. L. Hale \& S. J. Keyser (Eds.), The view from Building 20: Essays in linguistics in honor of Sylvain Bromberger (pp. 53-109). Boston, MA: Massachussets Institute of Technology.

- (2002). Prolegomenon to a Theory of Argument Structure. Cambridge, MA: MIT Press.

Harley, H. (2013). External arguments and the Mirror Principle: On the distinctness of Voice and v. Lingua, $125,34-57$.

Harley, H.; \& Noyer, R. (2000). Formal versus encyclopedic properties of vocabulary: Evidence from nominalizations. In B. Peeters (Ed.), The Lexicon-Encyclopedia Interface. Amsterdam: Elsevier.

Härtl, H. (2003). Conceptual and grammatical characteristics of argument alternations: The case of decausative verbs. Linguistics, 41(5), 883-916.

Haspelmath, M. (1993). More on the typology of inchoative/causative verb alternations. In B. Comrie \& M. Polinsky (Eds.), Causatives and transitivity (pp. 87-121). Amsterdam-Philadelphia, PA: John Benjamins.

Haspelmath, M.; Calude, A.; Spagnol, M.; Narrog, H.; \& Bamyaci, E. (2014). Coding causal-noncausal verb alternations: A form-frequency correspondence explanation. Journal of Linguistics, 50(3), 587-625.

Heidinger, S. (2014). The persistence of labile verbs in the French causative-anticausative alternation. Linguistics, 52(4), 1003-1024.

- (2015). Causalness and the encoding of the causative-anticausative alternation in French and Spanish. Journal of Linguistics, 51(3), 562-594. 
Horvath, J.; \& Siloni, T. (2011). Causatives across components. Natural Language \& Linguistic Theory, 29(3), 657-704.

[GIEC]: Institut d'Estudis Catalans (2016). Gramàtica de la llengua catalana. Barcelona: Institut d'Estudis Catalans.

Koontz-Garboden, A. (2009). Anticausativization. Natural Language \& Linguistic Theory, 27(1), 77-138.

Labelle, M.; \& Doron, E. (2010). Anticausative derivations (and other valency alternations) in French. Probus, 22(2), 303-316.

Levin, B.; \& Rappaport Hovav, M. (1995). Unaccusativity: At the Syntax-Lexical Semantics Interface. Cambridge, MA-London: The MIT Press.

- (2008). Lexicalized manner and result are in complementary distribution. In Y. N. Falk (Ed.), Proceedings of the Israel Association for Theoretical Linguistics 24 (pp. 1-16). The Hebrew University of Jerusalem.

. (2013). Lexicalized meaning and manner/result complementarity. In B. Arsenijević, B. Gehrke \& R. Marín (Eds.), Studies in the composition and decomposition of event predicates (pp. 49-70). Amsterdam: Springer.

Marantz, A. (1997). No escape from syntax: Don't try morphological analysis in the privacy of your own lexicon. University of Pennsylvania Working Papers in Linguistics. Proceedings of the 21st Annual Penn Linguistics Colloquium, 4(2), 201-225.

- (2001). Words. Treball presentat al 20th West Coast Conference on Formal Linguistics. University of Southern California.

. (2005). Objects out of the lexicon! Argument-structure in the syntax. Treball presentat al Third Cambridge Postgraduate Conference in Language Research (Vol. 18). University of Cambridge.

Mateu, J.; \& Acedo-Matellán, V. (2012). The manner/result complementarity revisited: a syntactic approach. In M. C. Cuervo \& Y. Roberge (Eds.), The end of argument structure? (pp. 209-228). Bingley: Emerald.

McKoon, G.; \& Macfarland, T. (2000). Externally and internally caused change of state verbs. Language, $76(4), 833-858$.

Mendikoetxea, A. (1999). Construcciones inacusativas y pasivas. In V. Demonte \& I. Bosque (Eds.), Gramática descriptiva de la lengua española (pp. 1575-1630). Madrid: Espasa-Calpe.

Neeleman, A.; \& Van de Koot, H. (2012). The linguistic expression of causation. In M. Everaert, M. Marelj \& T. Siloni (Eds.), The Theta System: Argument Structure at the Interface (pp. 20-51). Oxford-New York: Oxford University Press.

Piñón, C. (2001a). A finer look at the causative-inchoative alternation. In R. Hastings, B. Jackson \& Z. Zvolenszky (Eds.), Proceedings from Semantics and Linguistic Theory (pp. 346-364). Ithaca: Cornell University.

- (2001b). Modelling the causative-inchoative alternation. Linguistische Arbeitsberichte, 76, 273293.

Rákosi, G. (2012). In defence of the non-causative analysis of anticausatives. In M. Everaert, M. Marelj \& T. Siloni (Eds.), The Theta System: Argument Structure at the Interface (pp. 177-199). Oxford-New York: Oxford University Press.

Ramchand, G. C. (2008). Verb Meaning and the Lexicon: A First Phase Syntax. Cambridge, MA: Cambridge University Press. 
Rappaport Hovav, M. (2014). Lexical content and context: The causative alternation in English revisited. Lingua, 141, 8-29.

Rappaport Hovav, M.; \& Levin, B. (1998). Building verb meanings. In M. Butt \& W. Geuder (Eds.), The Projection of Arguments: Lexical and Compositional Factors (pp. 97-134). Stanford, CA: CSLI Publications.

- (2010). Reflections on manner/result complementarity. In M. Rappaport Hovav, E. Doron \& I. Sichel (Eds.), Syntax, lexical semantics, and event structure (pp. 21-38). Oxford-New York: Oxford University Press.

- (2012). Lexicon Uniformity and the Causative Alternation. In M. Everaert, M. Marelj \& T. Siloni (Eds.), The Theta System: Argument Structure at the Interface (pp. 150-176). Oxford-New York: Oxford University Press.

Reinhart, T. (2000). The theta system: Syntactic realization of verbal concepts. OTS Working Papers in Linguistics, (0-1), 1-70.

- (2003). The theta system-an overview. Theoretical linguistics, 28(3), 229-290.

- (2016). The theta system: Syntactic realization of verbal concepts. In M. Everaert, M. Marelj \& E. Reuland (Eds.), Concepts, Syntax, and their Interface: The Theta System (pp. 1-113). Cambridge, MALondon: The MIT Press.

Rigau, G. (2002). Els complements adjunts. In J. Solà, M.-R. Lloret, J. Mascaró \& M. Pérez Saldanya (Eds.), Gramàtica del català contemporani (pp. 2045-2110). Barcelona: Empúries.

Rodríguez, G. (2011). Why can't the sun bloom roses in Spanish?: On the nature of some internally-caused changes of state. Languages in Contrast, 11(2), 241-258.

Schäfer, F. (2008). The syntax of (anti-)causatives: external arguments in change-of-state contexts. AmsterdamPhiladelphia, PA: John Benjamins.

- (2009). The Causative Alternation. Language and Linguistics Compass, 3(2), 641-681.

Wolff, P. (2003). Direct causation in the linguistic coding and individuation of causal events. Cognition, $88(1), 1-48$.

Wright, S. K. (2001). Internally caused and externally caused change of state verbs. Tesi doctoral. Northwestern University.

. (2002). Transitivity and change of state verbs. In J. Larson \& M. Paster (Eds.), Proceedings of the Twenty-Eighth Annual Meeting of the Berkeley Linguistics Society (pp. 339-350). Berkeley, CA: Berkeley Linguistics Society. 
